\title{
MATLAB-Based Investigation of Multiphase Interleaved Buck-Boost Converter for PV System
}

\author{
Hardik P. Desai, ${ }^{1}$ Ranjan Maheshwari, ${ }^{2}$ and Shambhu N. Sharma ${ }^{3}$ \\ ${ }^{1}$ Department of Electrical Engineering, Sarvajanik College of Engineering \& Technology, Dr. R. K. Desai Marg, Athwalines, \\ Surat 395001, India \\ ${ }^{2}$ Department of Electronics Engineering, Rajasthan Technical University, Kota 324022, India \\ ${ }^{3}$ Department of Electrical Engineering, S. V. National Institute of Technology, Ichchhanath, Surat 395 007, India \\ Correspondence should be addressed to Hardik P. Desai, hardikpdesai@gmail.com
}

Received 30 September 2011; Accepted 9 November 2011

Academic Editor: S. Dai

Copyright (C) 2012 Hardik P. Desai et al. This is an open access article distributed under the Creative Commons Attribution License, which permits unrestricted use, distribution, and reproduction in any medium, provided the original work is properly cited.

A photovoltaic (PV) generator exhibits nonlinear voltage-current characteristics and its maximum power point varies with solar radiation. Analytical investigations of the new family of switching converters based on a parallel connection of $N(=4)$ identical buck-boost converters employed in PV system are presented. The interleaving strategy ensures that all the converters operate at the same switching frequency. Mathematical models developed using the state-space average technique are presented in this paper. Various steady-state performance expressions are also derived. The present converter system has the advantages of reduced size of the converter, and ripple in the total inductor current. The effectiveness of the four-phase interleaved dc-dc converter combined with PV system is demonstrated through simulations carried out in MATLAB environment.

\section{Introduction}

Generation of electrical energy from renewable sources has growing interest globally. As Photovoltaic (PV) power generator has advantages of no supply limitations, no pollution, and no noise, it can become the biggest contributor to electricity generation among all renewable energy sources. PV source is nonlinear power generator. Different techniques to maximise PV power transfer to various loads have been reported in the literature [1], some techniques only approximate the maximum power transfer of PV energy because they are associated with specific atmospheric and load conditions. In order to draw its maximum power, it is possible to insert dc-dc power converters between the PV and load. Power converters are required for many functions. A dc-dc converter converts a dc input voltage into a desired regulated $\mathrm{dc}$ output voltage $[2,3]$. The $\mathrm{dc}$ input may be an unregulated or regulated voltage. $\mathrm{dc} / \mathrm{dc}$ converters are widely used in photovoltaic generating systems as an interface between the photovoltaic panel and the load, allowing the follow-up of the maximum power point (MPP). These converters are known as maximum power point trackers (MPPTs). A maximum power point tracker should provide a maximum power to the load, even if irradiation, load, and temperature vary [4-8]. The dc-dc conversion process implies in turn an associated effect of impedance transformation, that is, the input impedance shows a dependence on a number of parameters such as load resistance, and duty cycle. Development of parallel connected converters with interleaving control strategies is coming up to increase the power processing capability and to improve the reliability of the power electronic system. In this paper, mathematical models are developed using state-space average technique for four-phase dc-dc converter employed with PV. Also various steady-state performance expressions are derived. Simulations carried out in MATLAB environment finds effectiveness of the four-phase interleaved dc-dc converter combined with PV system.

\section{Multiphase Interleaved Buck-Boost Converter}

Figure 1 shows the new family of switching converters based on a parallel connection of $N(=4)$ identical interleaved buck- 


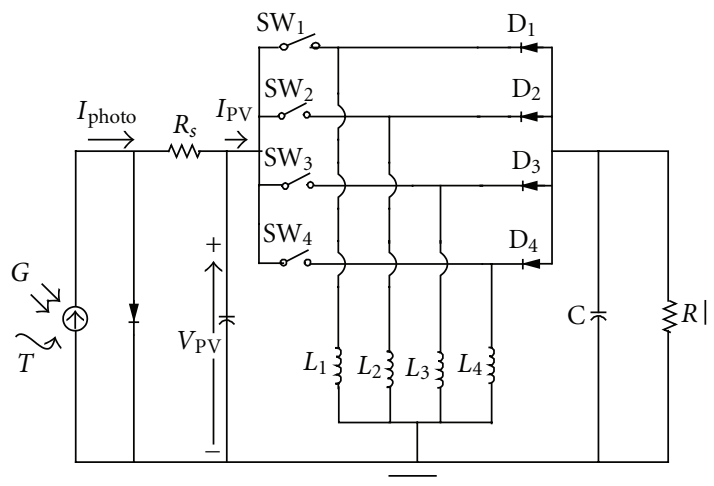

FiguRE 1: 4-phase interleaved buck boost converter with PV generator.

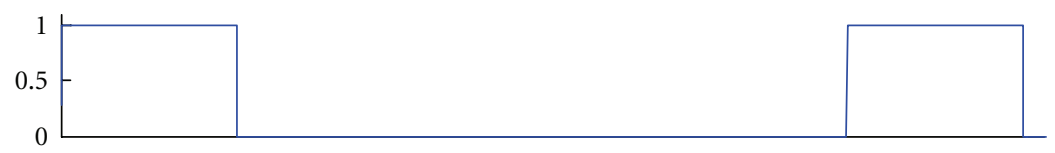

(a) PWM pulses applied to $\mathrm{SW}_{1}$

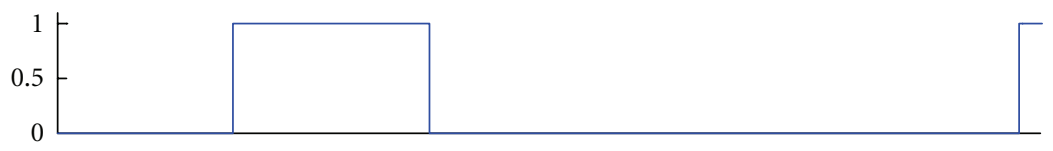

(b) PWM pulses applied to $\mathrm{SW}_{2}$

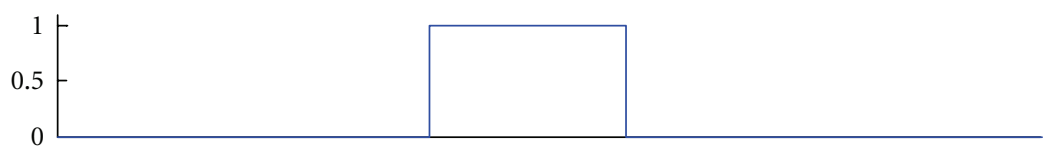

(c) PWM pulses applied to $\mathrm{SW}_{3}$

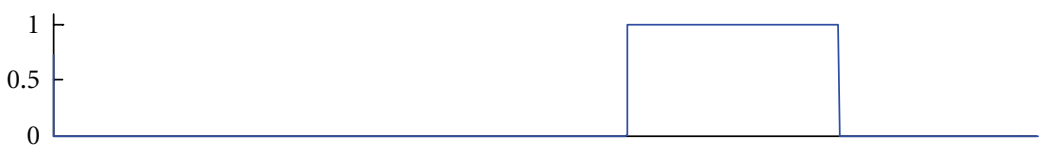

(d) PWM pulses applied to $\mathrm{SW}_{4}$

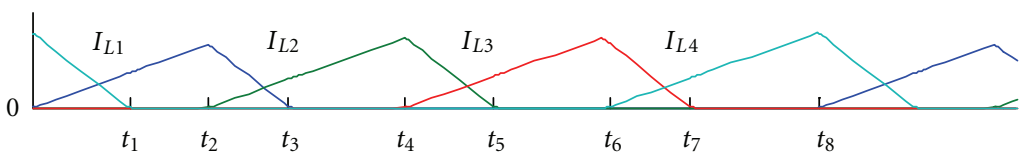

(e) Inductor current

Figure 2: (a)-(d) PWM pulses applied to switches $\mathrm{SW}_{1}-\mathrm{SW}_{4}$, (e) current through inductor.

boost converters employed in PV system which is considered for an analytical investigations.

A PV module consists of a combination of many small PV cells that are connected in series and parallel configurations to provide the desired voltage and current quantities. It is known that a PV cell module shows a nonlinear characteristic between voltage and current quantities, which is dependent on the insolation and temperature. The equation [9] which describe the I-V characteristics of the cell, is

$$
I_{\mathrm{PV}}=I_{\mathrm{PHOTO}}-I_{0}\left(e^{\left(q\left(V_{\mathrm{PV}}+I_{\mathrm{PV}} R_{S}\right) / n K T\right)}-1\right),
$$

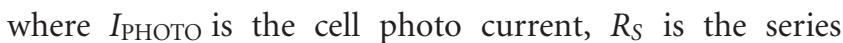
resistance of PV cell, $K$ is Boltzmann's constant, $q$ is charge on an electron, $n$ is the diode quality factor, $T$ is the cell temperature, and $V_{\mathrm{PV}}$ is the output voltage of PV cell. Reorganization of the equation provides the output voltage of the PV generator as

$$
V_{\mathrm{PV}}=\left(\frac{n K T}{q}\right) \ln \frac{\left(I_{0}+I_{\mathrm{PHOTO}}-I_{\mathrm{PV}}\right)}{I_{0}}-I_{\mathrm{PV}} R_{S},
$$

With $N$ identical cells connected in series and $M$ number of series combinations connected in parallel, the resultant voltage would be

$$
V_{\mathrm{PV}}=N\left(\frac{n K T}{q}\right) \ln \frac{\left(I_{0}+I_{\mathrm{PHOTO}}-I_{\mathrm{PV}}\right)}{I_{0}}-\frac{N I_{\mathrm{PV}} R_{S}}{M} .
$$




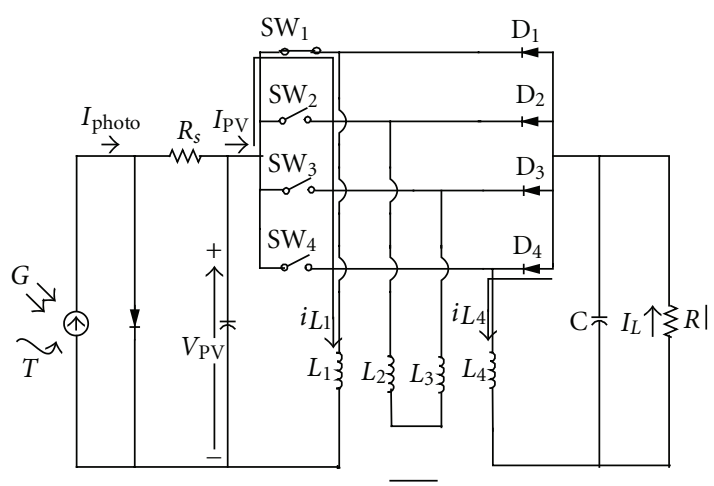

Figure 3: Mode 1.

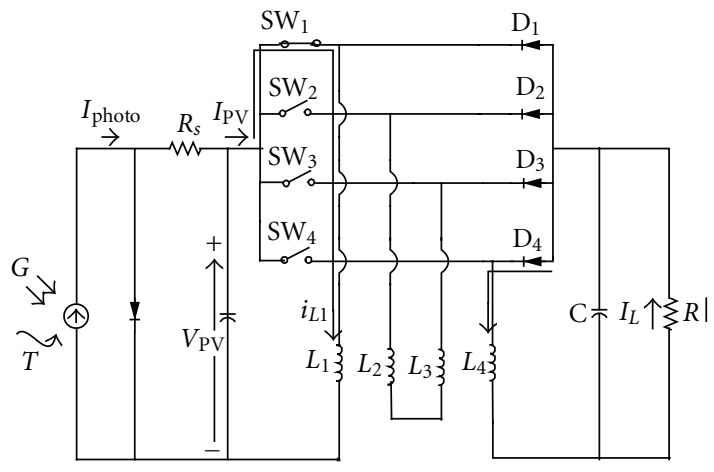

Figure 4: Mode 2.

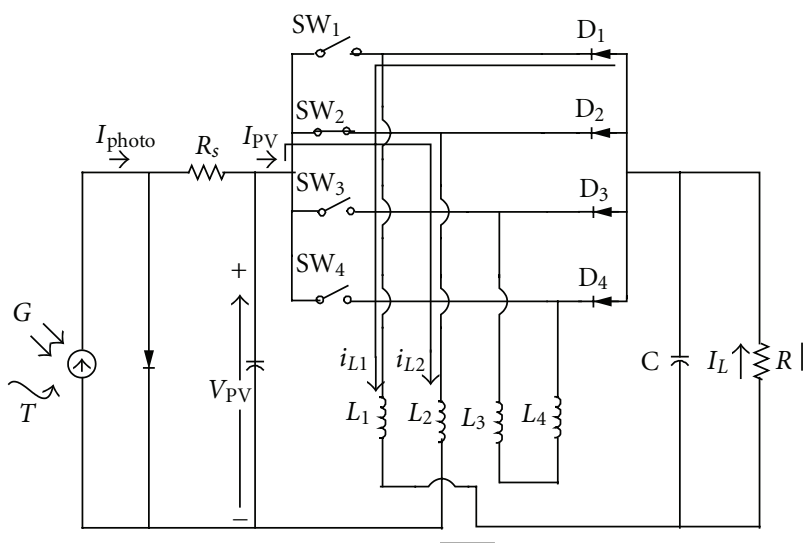

Figure 5: Mode 3.

To extract maximum power from the PV generator, MPP tracker is employed by connecting a dc-dc converter between the PV generator and load. Protection circuits like string combiners, blocking diodes, bypass diodes; and fuses can also be used in the circuit. String combiners are the physical point at which the leads from the PV generator circuits are joined in parallel to create the main array output. Each converter consists of a power MOSFET used as a controllable switch, an inductor $L$, a diode, a filter capacitor $C$, and a load resistor $R_{L}$.

With the interleaving PWM method, pulses are applied to the semiconductor switches such that $\mathrm{SW}_{1}, \mathrm{SW}_{2}, \mathrm{SW}_{3}$, and

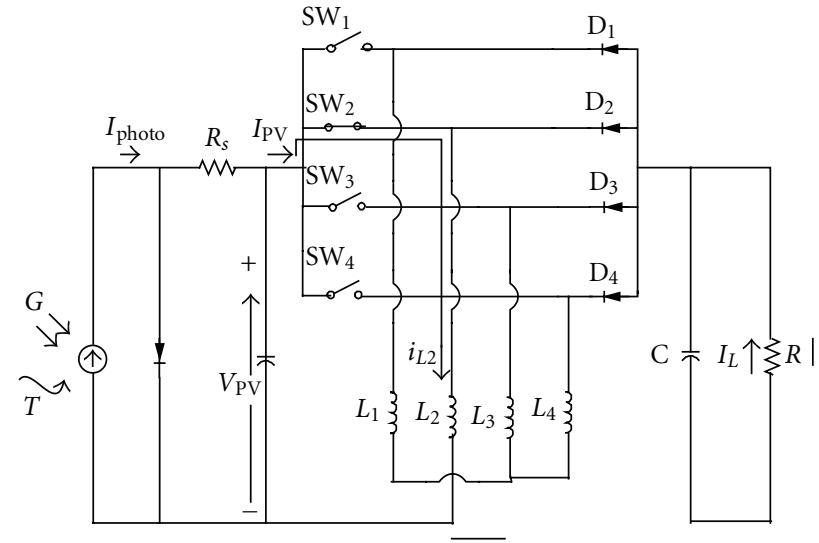

Figure 6: Mode 4.

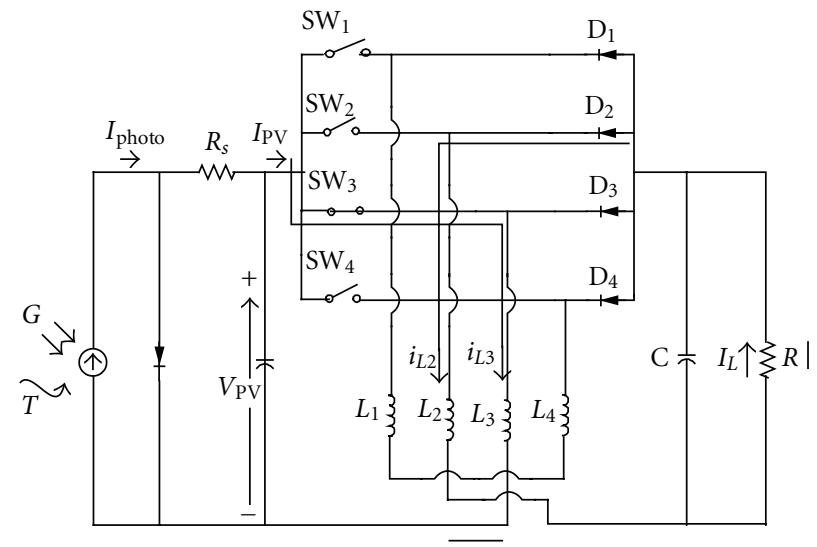

Figure 7: Mode 5.

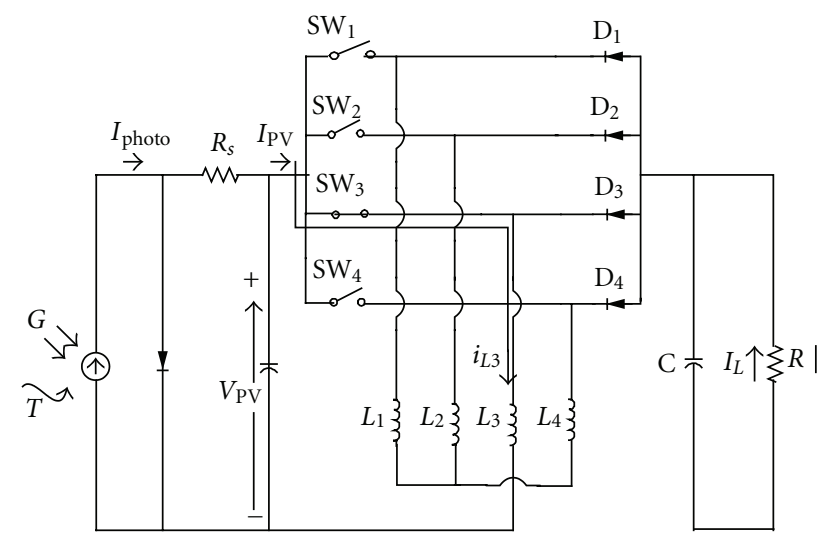

Figure 8: Mode 6.

$\mathrm{SW}_{4}$ are on and off in interleaving fashion as shown in Figure 2. Here, conduction period for the switches may be the same depending on the duty cycle of PWM pulses and $t_{1}+t_{2}+t_{3}+$ $t_{4}+t_{5}+t_{6}+t_{7}+t_{8}=T$, where $T$ is the total time period for switching with the on duty ratio $d=t_{\mathrm{on}} / T$, where $t_{\mathrm{on}}$ is the time interval when the switch is on. 


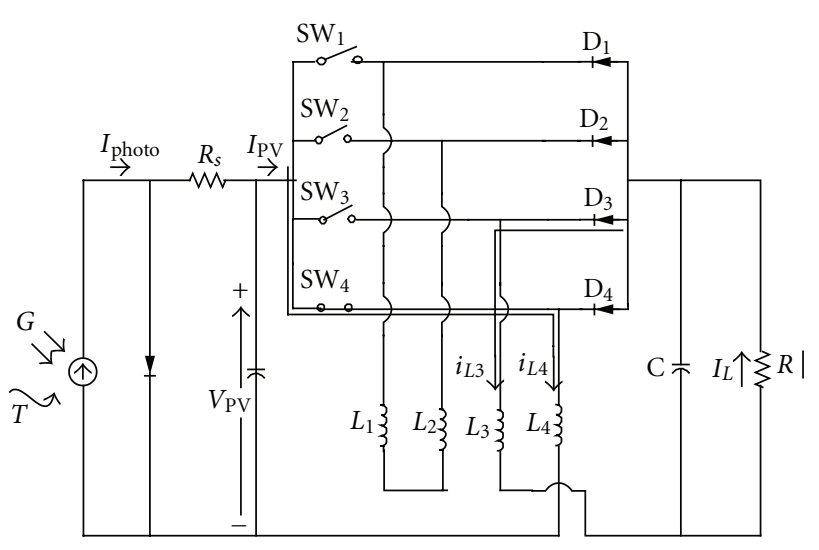

Figure 9: Mode 7.

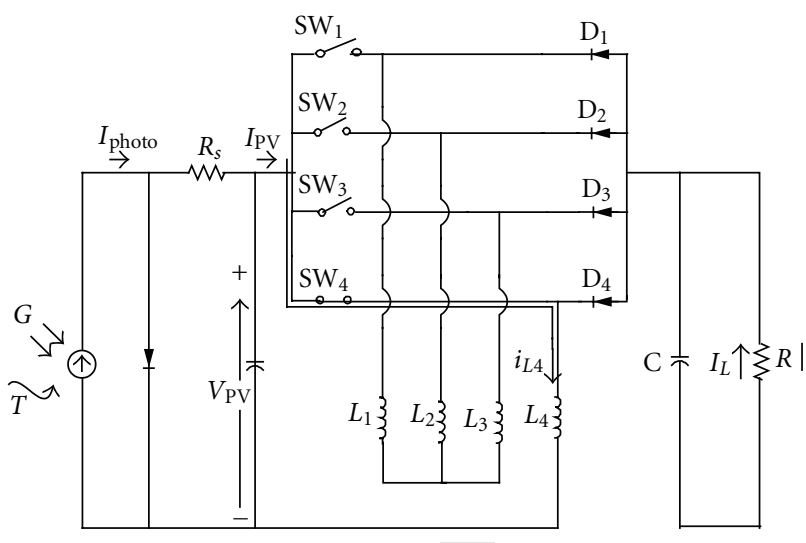

Figure 10: Mode 8.

Different modes of operation are as follows.

(i) Mode $1\left(0 \leq t \leq t_{1}\right)$. In this mode, $\mathrm{SW}_{1}$, and $\mathrm{D}_{4}$ are on and $\mathrm{SW}_{2}, \mathrm{SW}_{3}, \mathrm{SW}_{4}, \mathrm{D}_{1}, \mathrm{D}_{2}$, and $\mathrm{D}_{3}$ are off.

The state space equations for Figure 3 are

$$
\begin{aligned}
& \dot{i_{L 1}}=\frac{V_{\mathrm{PV}}}{L_{1}}-\frac{r_{L 1}}{L_{1}} i_{L 1}, \\
& \dot{i_{L 2}}=0, \\
& \dot{i_{L 3}}=0, \\
& \dot{i_{L 4}}=\frac{V_{L}}{L_{4}}-\frac{r_{L 4}}{L_{4}} i_{L 4}, \\
& \dot{V_{L}}=-\frac{i_{L 4}}{C}-\frac{V_{L}}{R_{L} C} .
\end{aligned}
$$

(ii) Mode $2\left(t_{1}<t \leq t_{2}\right)$. In this mode; $\mathrm{SW}_{1}$ is on and $\mathrm{SW}_{2}$, $\mathrm{SW}_{3}, \mathrm{SW}_{4}, \mathrm{D}_{1}, \mathrm{D}_{2}, \mathrm{D}_{3}, \mathrm{D}_{4}$ are off.

The state space equations for Figure 4 are

$$
\begin{aligned}
& \dot{i_{L 1}}=\frac{V_{\mathrm{PV}}}{L_{1}}-\frac{r_{L 1}}{L_{1}} i_{L 1}, \\
& \dot{i_{L 2}}=0,
\end{aligned}
$$

$$
\begin{aligned}
& \dot{i_{L 3}}=0, \\
& \dot{i_{L 4}}=0, \\
& \dot{V}_{L}=-\frac{V_{L}}{R_{L} C} .
\end{aligned}
$$

(iii) Mode $3\left(t_{2}<t \leq t_{3}\right)$. In this mode, $\mathrm{SW}_{2}$, and $\mathrm{D}_{1}$ are on and $\mathrm{SW}_{1}, \mathrm{SW}_{3}, \mathrm{SW}_{4}, \mathrm{D}_{2}, \mathrm{D}_{3}$, and $\mathrm{D}_{4}$ are off.

The state space equations for Figure 5 are

$$
\begin{aligned}
& \dot{i_{L 1}}=\frac{V_{L}}{L_{1}}-\frac{r_{L 1}}{L_{1}} i_{L 1}, \\
& \dot{i_{L 2}}=\frac{V_{\mathrm{PV}}}{L_{2}}-\frac{r_{L 2}}{L_{2}} i_{L 2}, \\
& \dot{i_{L 3}}=0, \\
& \dot{i_{L 4}}=0, \\
& \dot{V_{L}}=-\frac{i_{L 1}}{C}-\frac{V_{L}}{R_{L} C} .
\end{aligned}
$$

(iv) Mode $4\left(t_{3}<t \leq t_{4}\right)$. In this mode, $\mathrm{SW}_{2}$ is on and $\mathrm{SW}_{1}$, $\mathrm{SW}_{3}, \mathrm{SW}_{4}, \mathrm{D}_{1}, \mathrm{D}_{2}, \mathrm{D}_{3}$, and $\mathrm{D}_{4}$ are off.

The state space equations for Figure 6 are

$$
\begin{aligned}
& \dot{i_{L 1}}=0 \\
& \dot{i_{L 2}}=\frac{V_{\mathrm{PV}}}{L_{2}}-\frac{r_{L 2}}{L_{2}} i_{L 2} \\
& \dot{i_{L 3}}=0 \\
& \dot{i_{L 4}}=0 \\
& \dot{V_{L}}=-\frac{V_{L}}{R_{L} C} .
\end{aligned}
$$

(v) Mode $5\left(t_{4}<t \leq t_{5}\right)$. In this mode, SW3 and $\mathrm{D}_{2}$ are on and $\mathrm{SW}_{1}, \mathrm{SW}_{2}, \mathrm{SW}_{4}, \mathrm{D}_{1}, \mathrm{D}_{3}$, and $\mathrm{D}_{4}$ are off.

The state space equations for Figure 7 are

$$
\begin{aligned}
& \dot{i_{L 1}}=0, \\
& \dot{i_{L 2}}=\frac{V_{L}}{L_{2}}-\frac{r_{L 2}}{L_{2}} i_{L 2}, \\
& \dot{i_{L 3}}=\frac{V_{\mathrm{PV}}}{L_{3}}-\frac{r_{L 3}}{L_{3}} i_{L 3}, \\
& \dot{i_{L 4}}=0, \\
& \dot{V_{L}}=-\frac{i_{L 2}}{C}-\frac{V_{L}}{R_{L} C} .
\end{aligned}
$$

(vi) Mode $6\left(t_{5}<t \leq t_{6}\right)$. In this mode, $\mathrm{SW}_{3}$ is on and $\mathrm{SW}_{1}$, $\mathrm{SW}_{2}, \mathrm{SW}_{4}, \mathrm{D}_{1}, \mathrm{D}_{2}, \mathrm{D}_{3}$, and $\mathrm{D}_{4}$ are off.

The state space equations for Figure 8 are

$$
\begin{aligned}
& \dot{i_{L 1}}=0, \\
& \dot{i_{L 2}}=0, \\
& \dot{i_{L 3}}=\frac{V_{\mathrm{PV}}}{L_{3}}-\frac{r_{L 3}}{L_{3}} i_{L 3}, \\
& \dot{i_{L 4}}=0, \\
& \dot{V_{L}}=-\frac{V_{L}}{R_{L} C} .
\end{aligned}
$$




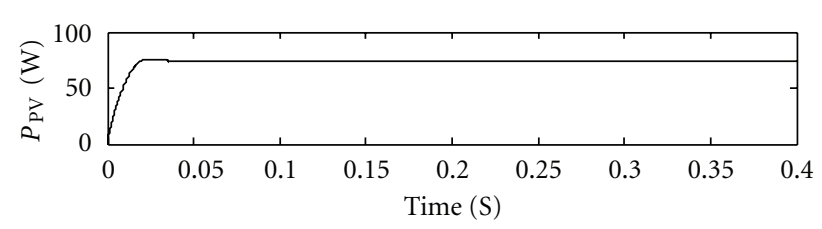

(a)

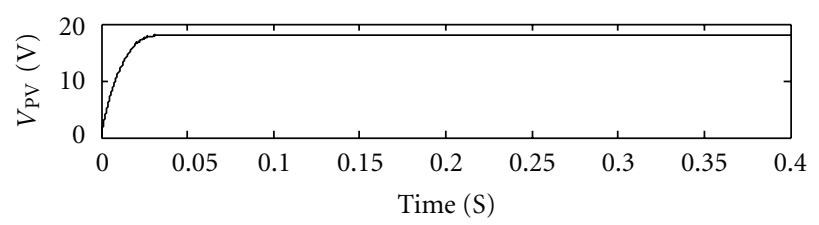

(b)

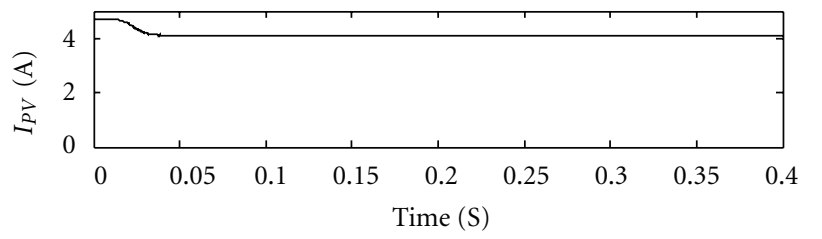

(c)

FIGURE 11: PV output (a) power, (b) voltage, and (c) current at MPP.

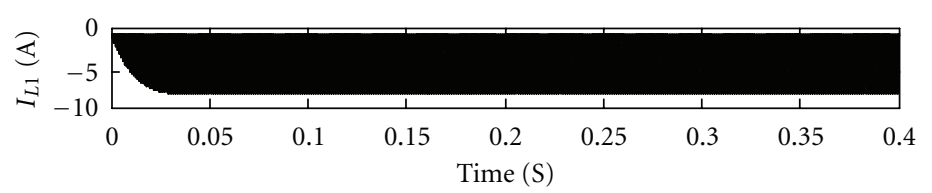

(a)

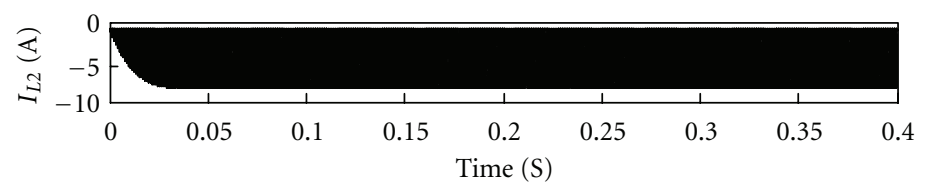

(b)

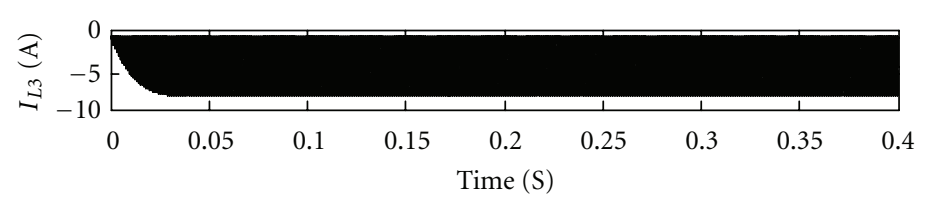

(c)

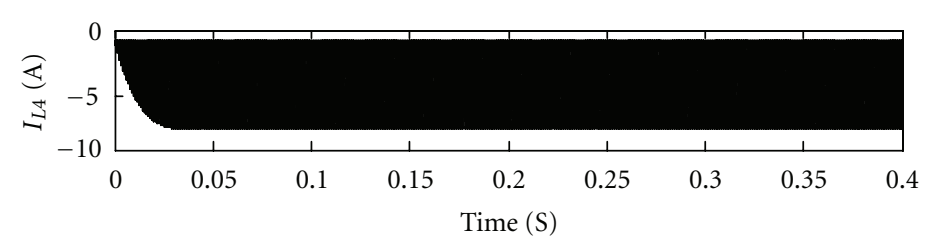

(d)

Figure 12: Current through inductors (a) $L_{1}$, (b) $L_{2}$, (c) $L_{3}$, and (d) $L_{4}$.

(vii) Mode $7\left(t_{6}<t \leq t_{7}\right)$. In this mode, $\mathrm{SW}_{4}$ and $\mathrm{D}_{3}$ are on and $\mathrm{SW}_{1}, \mathrm{SW}_{2}, \mathrm{SW}_{3}, \mathrm{D}_{1}, \mathrm{D}_{2}$, and $\mathrm{D}_{4}$ are off.

The state-space equations for Figure 9 are (viii) Mode $8\left(t_{7}<t \leq t_{8}\right)$. In this mode, $\mathrm{SW}_{4}$ is on and $\mathrm{SW}_{1}$, $\mathrm{SW}_{2}, \mathrm{SW}_{3}, \mathrm{D}_{1}, \mathrm{D}_{2}, \mathrm{D}_{3}$, and $\mathrm{D}_{4}$ are off.

The state-space equations for Figure 10 are

$$
\begin{aligned}
& \dot{i_{L 1}}=0, \\
& \dot{i_{L 2}}=0, \\
& \dot{i_{L 3}}=\frac{V_{L}}{L_{3}}-\frac{r_{L 3}}{L_{3}} i_{L 3}, \\
& \dot{i_{L 4}}=\frac{V_{P V}}{L_{4}}-\frac{r_{L 4}}{L_{4}} i_{L 4}, \\
& \dot{V_{L}}=-\frac{i_{L 3}}{C}-\frac{V_{L}}{R_{L} C} .
\end{aligned}
$$

$$
\begin{aligned}
& \dot{i_{L 1}}=0, \\
& \dot{i_{L 2}}=0, \\
& \dot{i_{L 3}}=0, \\
& \dot{i_{L 4}}=\frac{V_{\mathrm{PV}}}{L_{4}}-\frac{r_{L 4}}{L_{4}} i_{L 4}, \\
& \dot{V_{L}}=-\frac{V_{L}}{R_{L} C} .
\end{aligned}
$$


From, the above equations,

$$
\begin{aligned}
& \dot{i_{L 1}}=\left(d_{1}+d_{2}\right) \frac{V_{\mathrm{PV}}}{L_{1}}-\left(d_{1}+d_{2}+d_{3}\right) \frac{r_{L 1}}{L_{1}} i_{L 1}+d_{3} \frac{V_{L}}{L_{1}}, \\
& \dot{i_{L 2}}=\left(d_{3}+d_{4}\right) \frac{V_{\mathrm{PV}}}{L_{2}}-\left(d_{3}+d_{4}+d_{5}\right) \frac{r_{L 2}}{L_{2}} i_{L 2}+d_{5} \frac{V_{L}}{L_{2}}, \\
& \dot{i_{L 3}}=\left(d_{5}+d_{6}\right) \frac{V_{\mathrm{PV}}}{L_{3}}-\left(d_{5}+d_{6}+d_{7}\right) \frac{r_{L 3}}{L_{3}} i_{L 3}+d_{7} \frac{V_{L}}{L_{3}},
\end{aligned}
$$

$$
\begin{aligned}
& \dot{i_{L 4}}=d_{1} \frac{V_{L}}{L_{4}}+\left(d_{7}+d_{8}\right) \frac{V_{\mathrm{PV}}}{L_{4}}-\left(d_{1}+d_{7}+d_{8}\right) \frac{r_{L 4}}{L_{4}} i_{L 4}, \\
& \dot{V}_{\mathrm{L}}=-\frac{i_{L 1} d_{3}+i_{L 2} d_{5}+i_{L 3} d_{7}+i_{L 4} d_{1}}{C}-\frac{d V_{L}}{R_{L} C},
\end{aligned}
$$

where $d=d_{1}+d_{2}+d_{3}+d_{4}+d_{5}+d_{6}+d_{7}+d_{8}$.

Further simplifying the above equations,

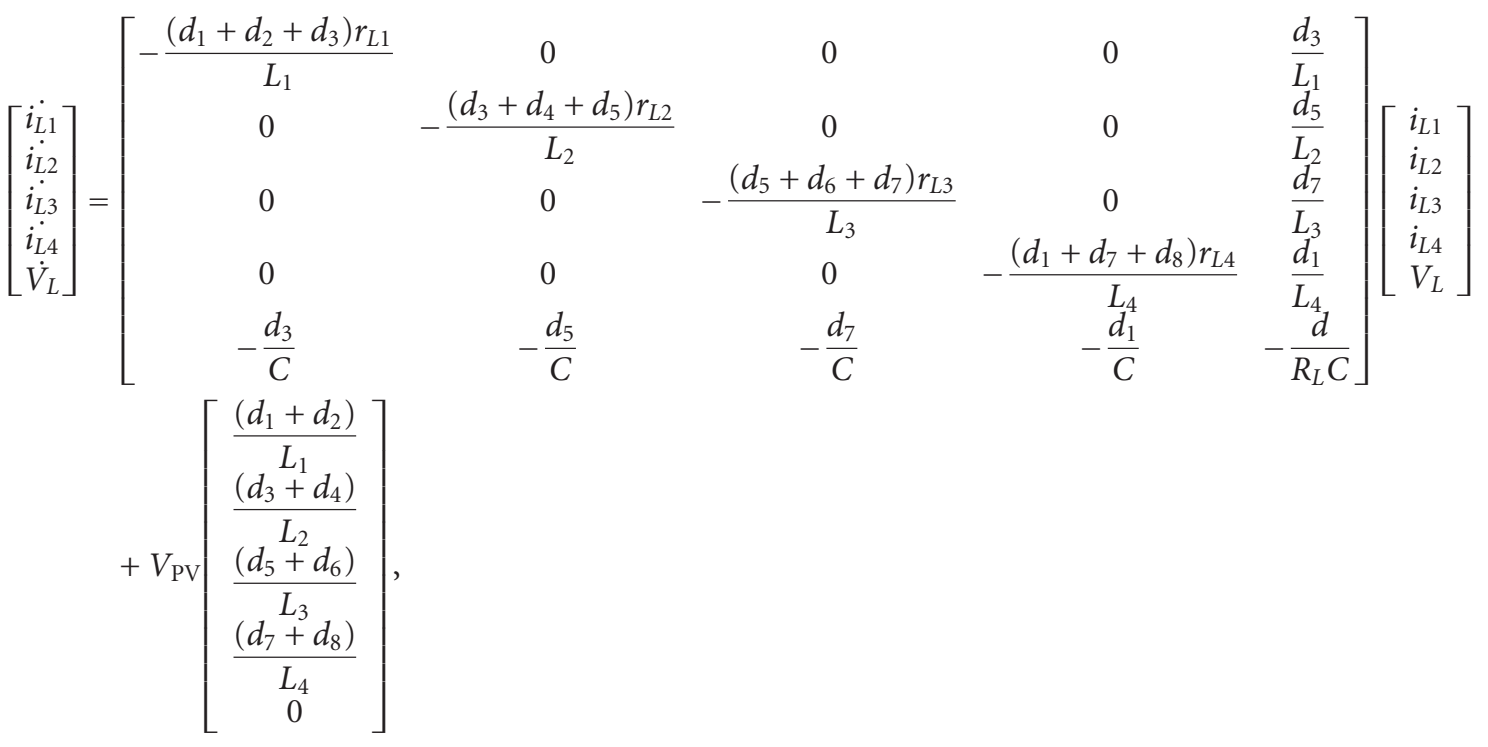

where, $i_{L n}$ : is the inductor current of $n$th phase converter, $L_{n}$ : is the inductance of phase $n$.

Considering the operation of converter $1, d_{1}+d_{2}=d$ and $d_{3}=d^{\prime}$, converter $2, d_{3}+d_{4}=d$ and $d_{5}=d^{\prime}$, and so on, $r_{1}=r_{2}=r_{3}=r_{4}=r$ and $L_{1}=L_{2}=L_{3}=L_{4}=L$, output voltage is given by

$$
V_{L}=-\frac{d V_{\mathrm{PV}}}{d^{\prime}}
$$

where $d^{\prime}$ is the duty cycle when the converter is supplied to load and after that inductor current becomes zero.

The previous equation describes the output voltage function of dc-dc converter. Input voltage of the converter $\left(V_{\mathrm{PV}}\right)$ can be adjusted to maximum power point by adjusting the duty cycle. The maximum switch and diode peak currents are given by

$$
I_{S N M}=I_{D N M}=\left(\frac{V_{\mathrm{PV}} T\left(d_{N}+d_{N+1}\right)}{2 L_{N}}\right),
$$

Where $M$ tends for maximum values.

For multiphase interleaved dc-dc converter, losses occur in MOSFETs, diodes, inductor, output capacitor, and so forth.

Losses that occurred in switches

$$
=\sum_{i=1}^{N} r_{\text {swi }} I_{\text {swir }}^{2}+f C_{\text {swi }}\left(V_{\mathrm{PV}}+V_{L}\right)^{2},
$$

where $I_{\text {swir }}=\Delta i_{L} \sqrt{\left(d_{i}+d_{i+1}\right) / 3}$.

Losses that occured in diodes

$$
=\sum_{i=1}^{N} r_{\mathrm{di}} I_{\mathrm{di} r}^{2}+V_{F i} I_{\mathrm{di}},
$$

where $I_{\mathrm{dir}}=\Delta i_{L} \sqrt{\left(d_{i}+d_{i+1}\right) / 3}$.

Inductor conduction losses

$$
=\sum_{i=1}^{N} r_{L i} I_{L r i}^{2} \text {, }
$$

where $I_{L r i}=\Delta i_{L} \sqrt{\left(d_{2 i-1}+d_{2 i}+d_{2 i+2}\right) / 3}$.

Losses that occurred in output capacitor

$$
=r_{c} I_{r c}^{2}
$$

Total losses

$$
\begin{aligned}
=\sum_{i=1}^{N}[ & r_{\mathrm{swi}} I_{r \mathrm{swi}}^{2}+f C_{\mathrm{swi}}\left(V_{\mathrm{PV}}+V_{L}\right)^{2} \\
& \left.+r_{\mathrm{di}} I_{r \mathrm{di}}^{2}+V_{F i} I_{\mathrm{di}}+r_{L i} I_{L r i}^{2}\right]+r_{c} I_{r c}^{2},
\end{aligned}
$$

where $r_{\text {swi }}$ and $r_{\mathrm{di}}$ are switch resistance diode resistance, respectively; $V_{F}$ is the forward voltage of diode, and suffix 


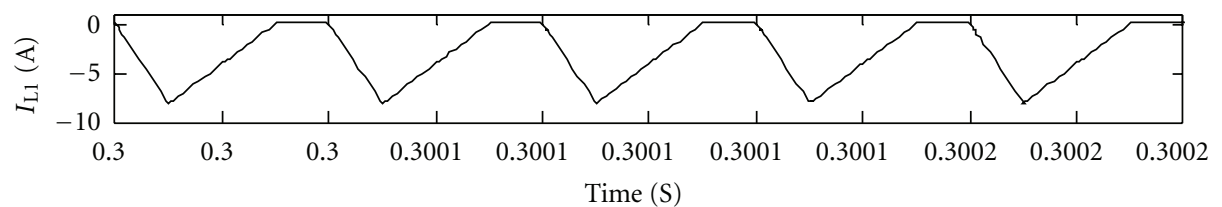

(a)

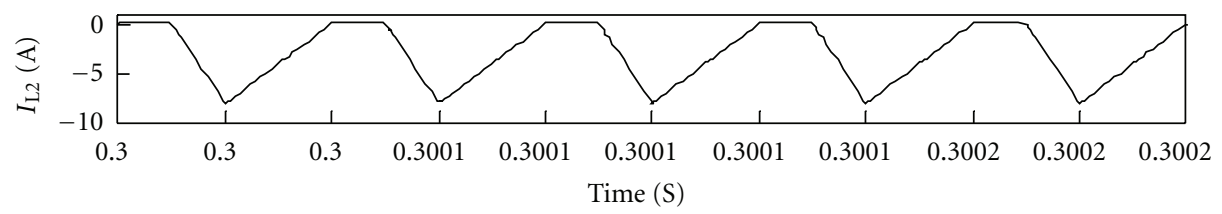

(b)

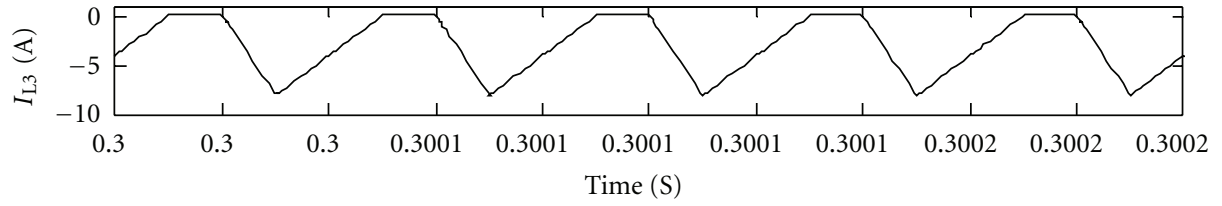

(c)

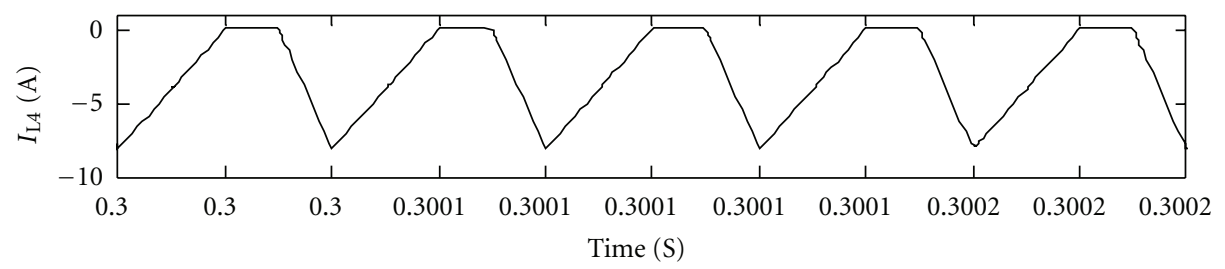

(d)

FIGURE 13: Current through inductors (a) $L_{1}$, (b) $L_{2}$, (c) $L_{3}$, and (d) $L_{4}$.

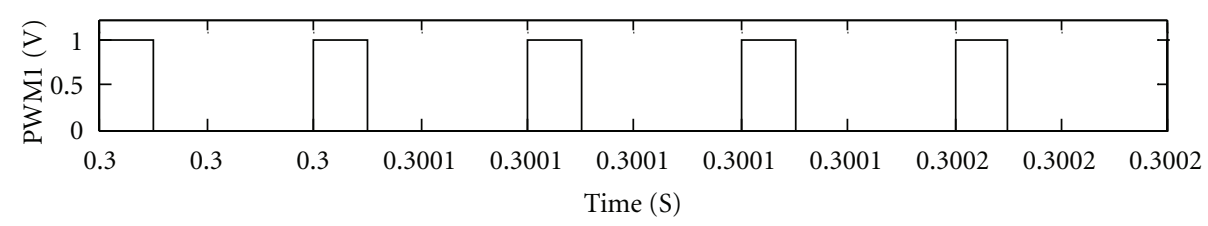

(a)

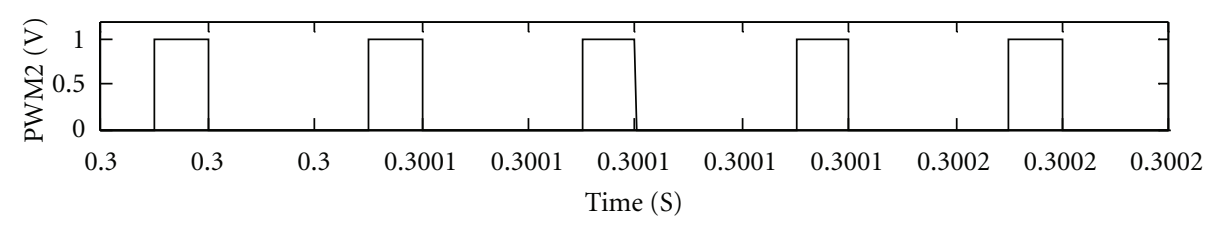

(b)

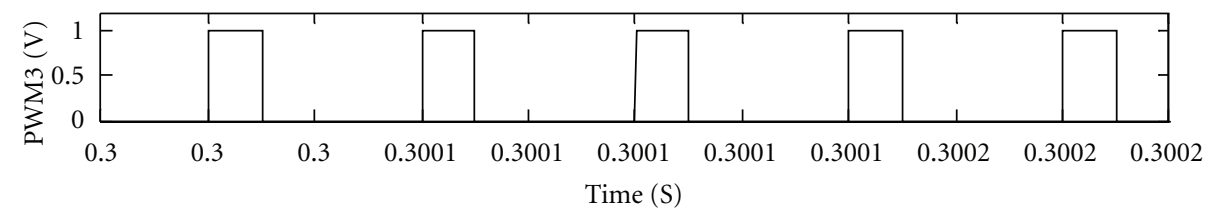

(c)

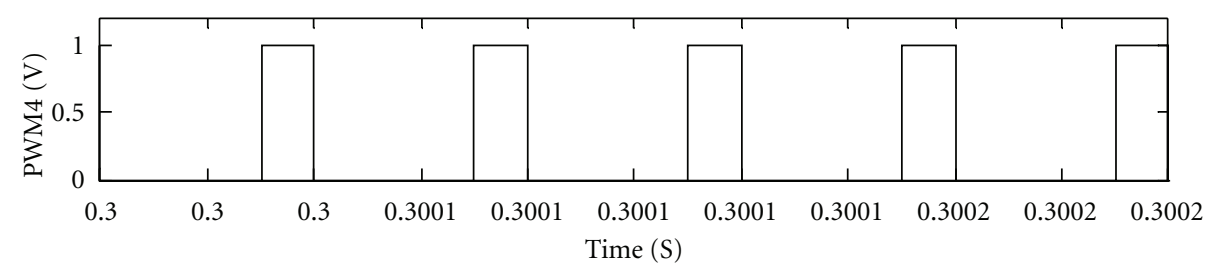

(d)

Figure 14: PWM pulses applied to (a) $\mathrm{SW}_{1}$, (b) $\mathrm{SW}_{2}$, (c) $\mathrm{SW}_{3}$, and (d) $\mathrm{SW}_{4}$. 


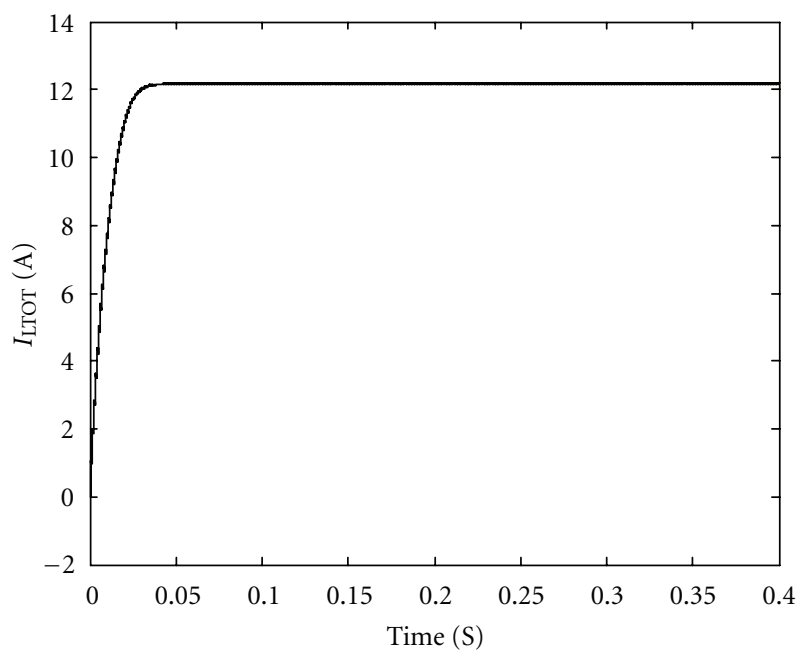

FIgURE 15: Total inductor current.

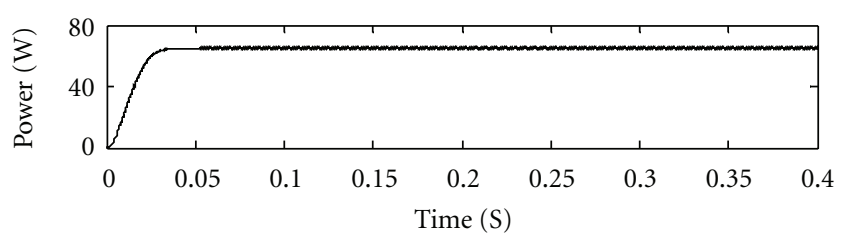

(a)

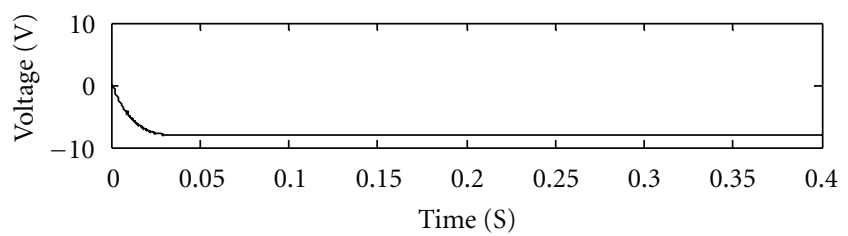

(b)

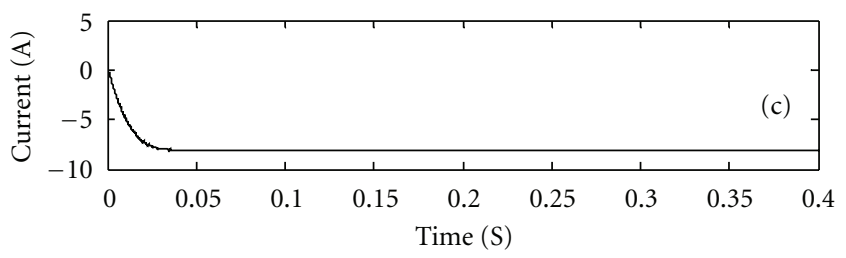

(c)

FIgURE 16: Converter output (a) power, (b) voltage and (c) current at MPP.

$r$ tends to rms value. Thus, the converter efficiency is given by,

$$
\eta=\frac{P_{L}}{P_{L}+\text { Total Losses }} .
$$

\section{Simulation Results}

The following parameters are used for simulation. PV generator parameters [10]: open circuit voltage: $21.8 \mathrm{~V}$; short circuit current: $4.7 \mathrm{~A}$; power at $\mathrm{MPP}=75 \mathrm{~W}$; converter parameters: switching frequency $=25 \mathrm{kHz} ; r_{L 1}=r_{L 2}=r_{L 3}=$ $r_{L 4}=0.01 \Omega, L_{1}=L_{2}=L_{3}=L_{4}=20 \mu \mathrm{H}, C=1000 \mu \mathrm{F}, V_{F}=$ $0.1 \mathrm{~V} ; r_{C}=0.06 \Omega$.

It was found that maximum power is extracted from PV generator with 4-phase interleaved dc-dc converter as shown in Figure 11 in which PV power (a) voltage (b) and current (c) at MPP is shown. At MPP, power of $74.3 \mathrm{~W}$ is extracted with voltage of $18.1 \mathrm{~V}$ and current of $4.1 \mathrm{~A}$ from PV. Figure 12 shows the current through inductors $L_{1}$ to $L_{4}$. Current through inductors for time duration of 0.3 to $0.3002 \mathrm{~s}$ are shown in Figure 13.

Figure 14 shows the pulse pattern applied to $\mathrm{SW}_{1}$ to $\mathrm{SW}_{4}$. It can be seen that one out of four converters is in operation with PV at a time. As shown in Figure 15, which shows total inductor current continuous in nature, the ripple current reduced significantly. Figure 16 shows the converter output power (a), voltage (b), and current (c) for the given MPP condition. At MPP, power of $65.1 \mathrm{~W}$ with voltage of $8.07 \mathrm{~V}$ and current of $8.07 \mathrm{~A}$ is available at load.

\section{Conclusion}

By using the state-space averaging technique, mathematical models are developed for parallel connected 4 identical buckboost converters employed in PV system. The interleaving strategy employed for PWM pulses ensures that all the converters operate at the same switching frequency. Various steady-state performance expressions were derived. The present converter system has the advantages of reduced size 
of the converter as inductor size is reduced; total inductor current is continuous although individual inductor current is discontinuous. The maximum power tracking effectiveness of the four-phase interleaved dc-dc converter combined with PV system is demonstrated through simulations carried out in MATLAB environment.

\section{References}

[1] H. K. Patel and H. P. Desai, "Maximum power point algorithm in PV generation: an overview," in Proceedings of the 7th International Conference on Power Electronics and Drive Systems (PEDS '07), pp. 624-630, Bangkok, Thailand, November 2007.

[2] B. Kazimierczuk and M. K. Bryant, "Derivation of the buckboost PWM DC-DC converter circuit topology," in Proceedings of the International Symposium on Circuits and Systems, pp. 841-844, May 2002.

[3] T. M. Undeland, W. P. Robbins, and N. Mohan, Power Electronics: Converters, Applications, and Design, John Wiley \& Sons, 2nd edition, 1996.

[4] K. H. Hussein, I. Muta, T. Hoshino, and M. Osakada, "Maximum photovoltaic power tracking: an algorithm for rapidly changing atmospheric conditions," IEE Proceedings: Generation, Transmission and Distribution, vol. 142, no. 1, pp. 59-64, 1995.

[5] E. Durán, M. Sidrach-de-Cardona, J. M. Andújar, and J. M. Enrique, "Theoretical assessment of the maximum power point tracking efficiency of photovoltaic facilities with different converter topologies," Solar Energy, vol. 81, no. 1, pp. 3138, 2007.

[6] R. D. Middlebrook and S. Cuk, "A general unified approach to modelling switching converter power stages," in Proceedings of the Power Electronics Specialists Conference, pp. 18-34, Cleveland, Ohio, USA, June 1976.

[7] A. Gherlitz, Y. Berkovich, A. Ioinovici, and O. Abutbul, "Stepup switching-mode converter with high voltage gain using a switched-capacitor circuit," IEEE Transactions on Circuits and Systems I, vol. 50, no. 8, pp. 1098-1102, 2003.

[8] H. Dehbonei, E. F. Fuchs, and M. A. S. Masoum, "Theoretical and experimental analyses of photovoltaic systems with voltage- and current-based maximum power-point tracking," IEEE Transactions on Energy Conversion, vol. 17, no. 4, pp. 514-522, 2002.

[9] G. Walker, "Evaluating MPPT converter topologies using a MATLAB PV model," Journal of Electrical and Electronics Engineering, vol. 21, no. 1, pp. 49-55, 2001.

[10] Solar Data Sheets, http://www.bpsunoasis.com. 

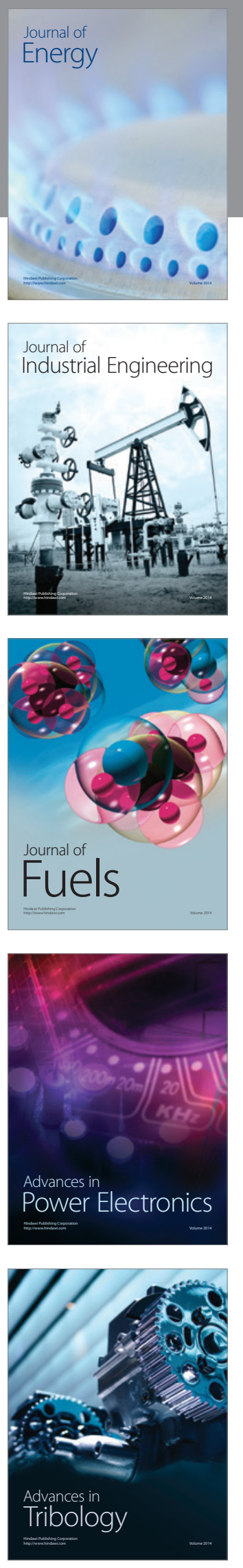
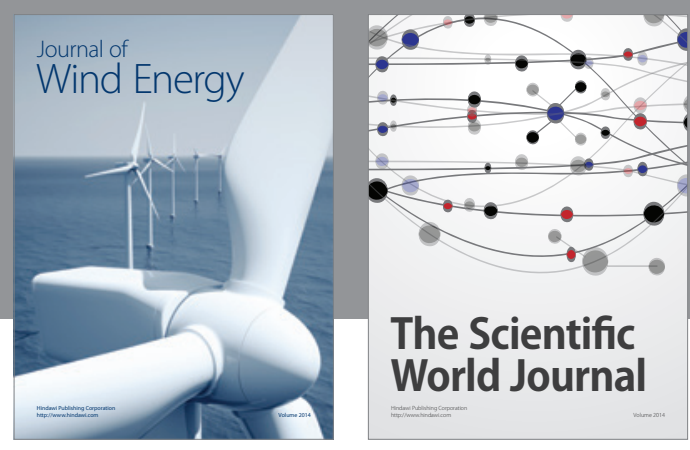

The Scientific World Journal

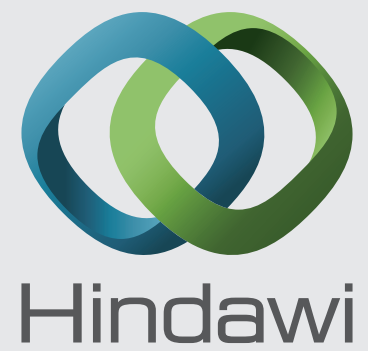

Submit your manuscripts at http://www.hindawi.com
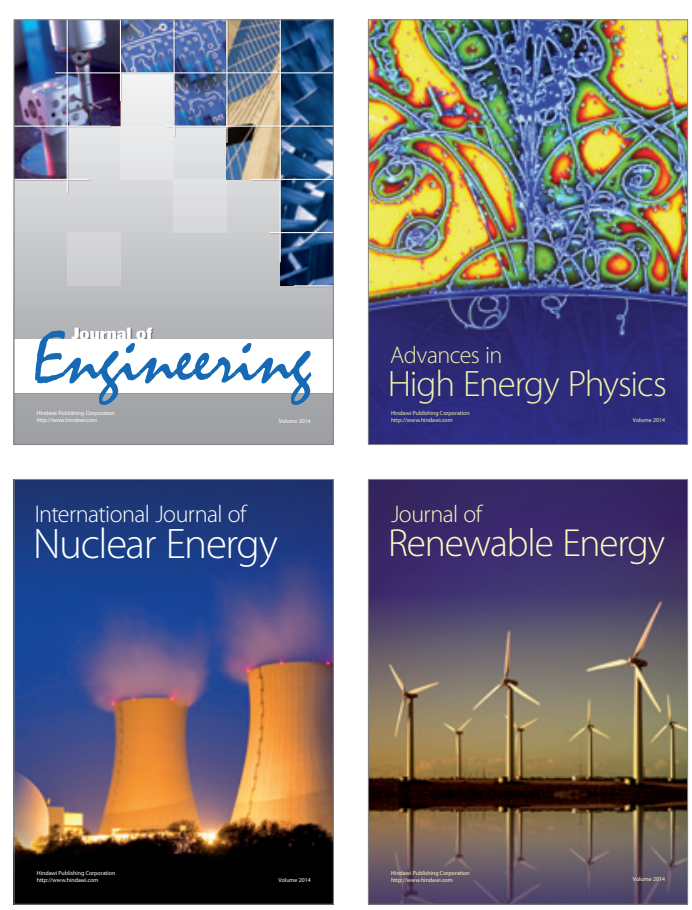

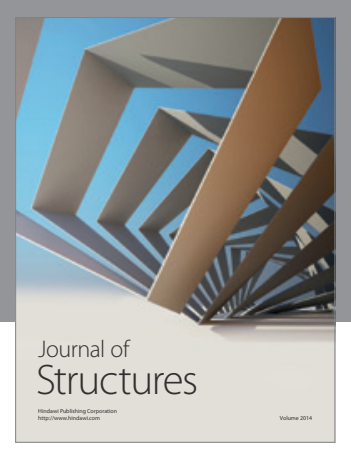

Rotating
Mechinery
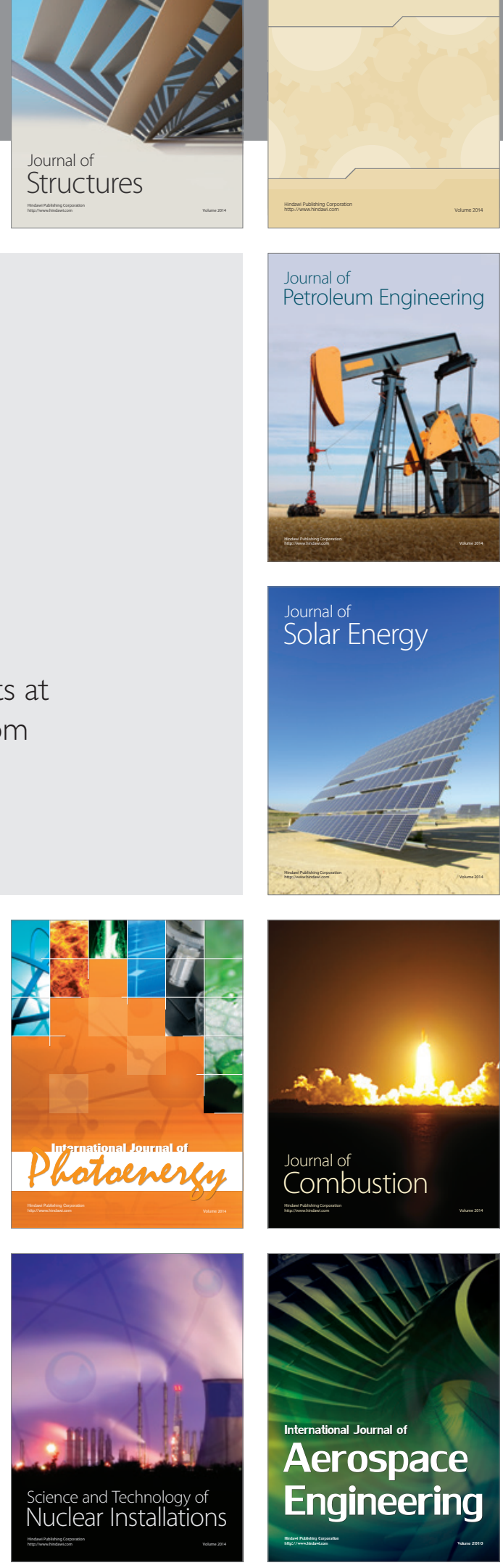